\title{
Photo-grammetric measurements of swimming speed and body length of basking sharks observed around the Hebrides, Scotland
}

\author{
CLAIRE LACEY $^{1}$, RUSSELL LEAPER ${ }^{1}$, ANNA MOSCROP ${ }^{1}$, DOUGLAS GILLESPIE ${ }^{2}$, RICHARD MCLANAGHAN ${ }^{1}$ \\ AND STEVE BROWN ${ }^{3}$ \\ ${ }^{1}$ International Fund for Animal Welfare, 87-90 Albert Embankment, London, SE1 7UD, ${ }^{2}$ Sea Mammal Research Unit, Gatty Marine \\ Labotatory, University of St Andrews, St Andrews, Fife, ${ }^{3}$ Ocean Alliance, 191 Weston Road, Lincoln, MA 01773 USA
}

\begin{abstract}
Photo-grammetric techniques developed for measuring body length and small scale movement patterns of cetaceans were applied to surface swimming basking sharks off the west coast of Scotland. These methods removed the need for close approaches, reducing the likelihood of disturbing the focal animal. Average swimming speed was calculated from the total path length between shark locations measured at approximately one minute intervals. These average speeds varied from 0.49 to $0.73 \mathrm{~ms}^{-1}$ for tracks of between 30 and 170 minutes' duration. Body length measurements ranged between 2.35 and $6.43 \mathrm{~m}$. For ten sharks where body length and swimming speed were measured there was a significant correlation between body length $(L)$ and swimming speed $(V)$ expressed as $\mathrm{V}=0.36 L^{033}$.
\end{abstract}

Keywords: basking shark, photo-grammetric techniques, size estimation

Submitted 7 November 2008; accepted 5 March 2009; first published online 10 August 2009

\section{INTRDDUCTION}

The basking shark (Cetorhinus maximus) is one of three filter feeding shark species and can attain body lengths of up to $10 \mathrm{~m}$ (Matthews \& Parker, 1950). Its feeding strategy, known as ram filter-feeding (Sims, 2000), is unique among sharks. The flow of water through the large open mouth is controlled by swimming speed unlike the suction feeding methods of whale shark (Rhynocodon typus) and megamouth shark (Megachasma pelagios). Thus there is potential for estimating the amount of prey consumed in relation to body size based on observations made at sea.

Several studies have examined the relationship between swim speed, energy consumption and plankton concentrations in basking sharks (Sims \& Quayle, 1998; Sims et al., 1997; Sims 1999, 2000), but previous methods of measuring body length and swim speed have relied on very close approaches to the animals. This limited the number of measurements that could be made and also increased the risk of disturbance by the study vessel, which could have led to unrepresentative behaviour. The main aims of this study were to measure body lengths and swimming speeds and to investigate the relationship between them. Photo-grammetric methods were used to allow these data to be collected at ranges of around $100 \mathrm{~m}$ to the study animal. The methods used were developed for measuring the lengths

Corresponding author:

C. Lacey

Email: clacey@ifaw.org
(Gordon, 1990) and small scale movement patterns (Denardo et al., 2001; Leaper \& Gordon, 2001) of cetaceans but can potentially be applied to any species visible at the sea surface.

\section{MATERIALS AND METHDDS}

Dedicated visual searches for basking sharks were conducted around the Small Isles off the west coast of Scotland between 2 and 23 September 2002 from the 'Song of the Whale', a $14 \mathrm{~m}$ auxiliary powered sailing research vessel. Two visual observers searched either side of the vessel from a viewing platform with an eye height of around $5 \mathrm{~m}$. Sightings of all cetaceans and basking sharks were recorded together with environmental data and the location of the vessel (based on differential GPS) using the dedicated 'Logger' data entry software. Whenever basking sharks were encountered the vessel approached and attempted to track the small scale movements of individuals.

\section{Tracking of small scale movements}

Tracking of animal movements at sea based on visual observations requires accurate measurement of the location of the research vessel together with the location of the tracked animal relative to the research vessel. Locations relative to the research vessel were based on measurement of distance

\footnotetext{
${ }^{1}$ This software package was developed by IFAW to contribute to benign research and is available for download from www.ifaw.org
} 
and bearing. Distances to objects on the sea surface can be calculated from photographic images by measuring the angle of dip from the horizon to the object from images taken from a known height with a calibrated lens. The lens calibration involved measuring the number of pixels on the video image that corresponded to a known angle subtended at the lens. Bearings were recorded verbally on video tape using binoculars fitted with a magnetic compass (Fujinon $7 \times 50$ Mariner). These methods have been used to track the movements of whales (Denardo et al., 2001; Leaper \& Gordon, 2001) and were also subjected to extensive calibration tests to assess their accuracy (Gordon, 2001; Leaper \& Gordon, 2001). The methods rely on the visual target being at the surface and so can be readily applied to any object if suitable images are obtained. Basking sharks spend considerable periods of time at the surface with a conspicuous dorsal fin and, therefore, are good candidates for such techniques. Whilst filming, it was necessary to ensure that both the focal shark and the horizon were within the field of view and the height of the camera above sea level was accurately recorded. Tracking of individual basking sharks was aborted whenever the presence of other sharks resulted in possible confusion over which shark was being tracked.

The mean eye height for observations was $5.2 \mathrm{~m}$ (varying between $4.95 \mathrm{~m}$ and $5.35 \mathrm{~m}$ for different observers). Sharks were tracked out to a maximum distance of $430 \mathrm{~m}$ with an average of $117 \mathrm{~m}$. In this study all tracking was carried out in calm sea conditions with winds of Beaufort force 3 or less. Swell conditions throughout were judged to be gentle with wave heights of less than $0.5 \mathrm{~m}$. However, swell height is notoriously difficult to judge from a small vessel in the open sea. In order to assess the likely errors related to the vertical movement of the vessel and sharks due to swell, a simple simulation study was used. Simulations were conducted on the assumption that the vertical displacement of the shark and the research vessel were independent and used the actual eye heights and measured distances from the study. These simulations indicated that a $0.5 \mathrm{~m}$ swell ( $1 \mathrm{~m}$ peak to peak) would generate a standard deviation (SD) of error/distance of 0.068 . For a swell height of $0.25 \mathrm{~m}$ which was judged representative of the worst swell conditions experienced, the SD would be 0.034 .

Measurements of range and bearing were made approximately once a minute. Total distance travelled was calculated as the sum of distances between observed locations. The one minute interval was chosen to be sufficiently small to include short term changes in shark swimming direction but not to be too small that random error in shark locations would cause a substantial bias in estimates of swim speed. All length measurements were made during the period of tracking an individual.

In order to allow comparison between movement over the ground and movement through the water, a drifting buoy, fitted with a hand-held GPS on a surface float with a drogue at $10 \mathrm{~m}$ depth, was deployed at the start of each tracking session and recovered at the end. The GPS was set to record its location every minute and these data were downloaded for each track to provide a measure of surface drift.

\section{Length measurement}

In addition to measuring locations, measurements from photographic images can also be used to estimate body size.
This has been successfully applied to whales (Gordon, 1990) by measuring the distance to easily identifiable parts of the whale's body and using angles measured from images to convert these to lengths. This is shown for a basking shark in Figure 1. Some of the sources of error in length measurement will be common to all species. These include errors in range due to incorrect calibration or changes in eye height, measurement errors from images and misjudgement of presentation angle. Errors or biases that may be more taxa specific are related to body flexing and extrapolating to total body length based on partial measurements.

For basking sharks observed at the surface the most conspicuous part of the body is the dorsal fin. In addition, the snout and tail fin are also frequently visible although not always at the same time. Thus the measurements that could be taken photo-grammetrically were either snout to dorsal, dorsal to tail, or snout to tail.

In order to calculate total length from the photogrammetric measurements comparisons were made with measurements from carcasses. Matthews \& Parker (1950) give detailed measurements from the carcasses of eight sharks caught in the region of the study area and brought ashore on the island of Soay in the Inner Hebrides. These sharks were all between 6.2 and $7.5 \mathrm{~m}$ long and consisted of three males and five females. Figure 2 shows some of the measurements given by Matthews \& Parker (1950) and the measurements that can be made from photographs. Examination of photographs of 17 dorsal fins indicated that the tip of the dorsal fin, which is the point of measurement for photographs, lies at $0.83(\mathrm{SD}=0.09)$ of the distance between the anterior base and the posterior edge, when measured along the axis of the shark's body. Thus:

$$
S=A+0.83(P-A)=0.83 P+0.17 A
$$

In addition, the line from the caudal emargination to the tip of the tail fin appears to lie at around $45^{\circ}$ to the axis of the sharks body, giving

$$
L=T+S-C / \sqrt{2}
$$

Thus $\mathrm{T}$ can also be expressed in terms of measurements from Matthews \& Parker (1950) as

$$
T=L+C / \sqrt{2}-0.83 P-0.17 A
$$

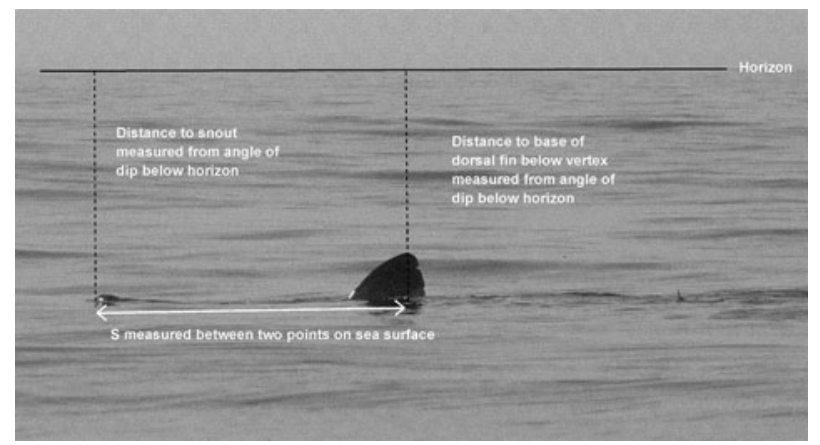

Fig. 1. Example of measurement of snout to dorsal length $(S)$. In this case, although the tail fin is just visible it appears to be at a different angle to the rest of the body and would not be used for length measurement. 


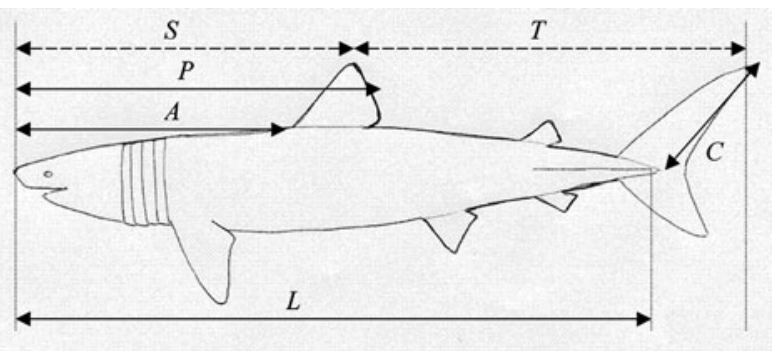

Fig. 2. Comparison of measurements from carcasses by Matthews \& Parker (1950) and measurements from photographs. S, snout to dorsal measurement by photo-grammetry; $\mathrm{T}$, dorsal to tail measurement by photo-grammetry; A, snout to anterior base of dorsal fin, Matthews \& Parker; P, snout to posterior edge of dorsal fin, Matthews \& Parker; C, centre of caudal emargination to tip of dorsal fin; L, total body length, snout to caudal emargination.

The mean $\mathrm{C} / \mathrm{L}$ from the measurements of Matthews \& Parker $(1950)$ was $0.18(\mathrm{SD}=0.01)$, and this is the value used in all calculations here. There was a strong correlation within their measurements $\left(r^{2}=0.91, \mathrm{df}=6, P<0.01\right)$ between $S$ as calculated in equation (1) and $L$. There was a slightly less strong correlation between $T$ as calculated from (3) and $L\left(\mathrm{r}^{2}=0.70, \mathrm{df}=6, P<0.01\right)$. The additional variance in $T$ appeared to be due to variability in the size of the tail fin $C$. Within the data set of Matthews \& Parker (1950), the correlation between $C$ and $L$ was not significant $\left(\mathrm{r}^{2}=\right.$ $0.05, \mathrm{df}=6, P>0.05$ ). For the purposes of relating body size to swimming speed we generated a 'best' estimate of $L$ based on the mean of all measurements obtained for an individual shark assuming $L=S \times 1.87, L=T \times 1.67, L=$ $(S+T) / 1.13$. However, we also considered the relationship with $T$ since this is the part of the body generating the propulsive force.

Both still and video images were used for length measurement. Still images were taken on $35 \mathrm{~mm}$ slide film and scanned using a Nikon LS-1000 $35 \mathrm{~mm}$ slide scanner. Video tapes were reviewed using a Sony digital video cassette recorder, DSR-V1oP. Images that were suitable for either tracking or length measurement were captured using a commercially available digital video capture card and software. For each video image grabbed, three others were taken within the same second, giving clusters of 4 measurements for the same, almost identical picture. These 'clusters' of pictures were used to examine some of the factors that could contribute to errors in length measurement. The variance in length estimates between pictures within a cluster was assumed to be due to errors in taking measurements from the image. These errors were assumed to be additive.

The mean range at which length measurements were made was $90 \mathrm{~m}(\mathrm{SD}=32)$ with a maximum of $215 \mathrm{~m}$. Seventy per cent of length measurements were taken at ranges between 60 and $120 \mathrm{~m}$. Errors in height due to swell would be expected to contribute a multiplicative error with an SD of around 0.034 based on the results of simulations.

The vertical axis of the shark tail fin makes measurements of shark length more susceptible to body flexing than those for whales. In order to investigate this further, a simple model for body flexing was developed based on observations of swimming in dogfish (Videler, 1993). Body flexing was modelled as a sine wave with amplitude $o$ at the head increasing to $a$ at the tail, where $a$ is expressed as a fraction of total length (Figure 3). Then the arc length $M$ as a ratio to the measured straight line length is given by

$$
M=\frac{1}{2 \pi} \int_{0}^{2 \pi} \sqrt{\left((2 \pi a x)^{2} \cos ^{2} x+1\right)} d x
$$

Based on a sequence of images in Videler (1993) for dogfish, $a$ was estimated as 0.17 . This would give a value for $M$ of 1.09 . This is clearly a very approximate value but if basking sharks alternate between a straight body and this amount of flexing this would result in mean length measurements being negatively biased by around $5 \%$.

These sources of error could be combined in an error model including the multiplicative errors related to body flexing and errors in distance and the additive error with SD of $\sigma$ related to measurement from images where $X$ is the true value of the section of body being measured.

$$
\hat{X}=\text { BodyFlexError } \times \text { RangeError } \times X+N(\mathrm{o}, \sigma)
$$

Errors due to lens calibration will not show up in the variance of the measured lengths unless the lens was recalibrated between measurements. However, there was no reason to suspect that these errors would be any greater than previous calibration tests (Gordon, 2001; Leaper \& Gordon, 2001) which indicate that lens calibration is a minor component of total error. Errors in measurement of the presentation angle

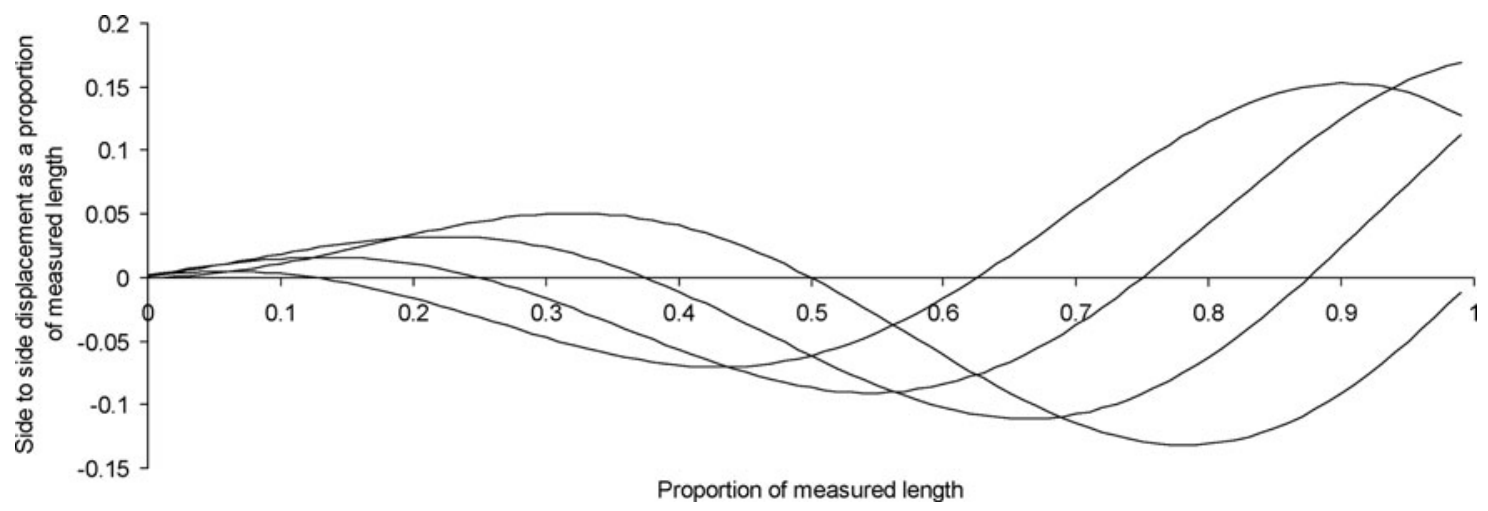

Fig. 3. Example of body flexing model used to investigate variance and bias in length measurements. Snout of shark is at $x=0$ and tip of tail at $x=1$. Dotted lines indicate positions of midline of body at different points in the swimming stroke. 


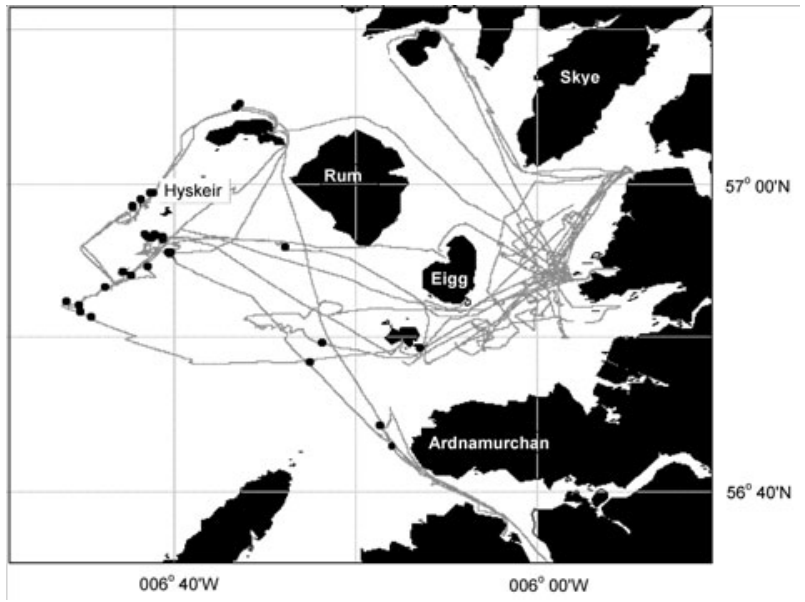

Fig. 4. Study area off the west coast of Scotland. Filled circles indicate locations of basking shark sightings. Lines indicate tracks sailed by the research vessel.

of the shark's body relative to the video camera will be an additional source of variance but this is confounded by the flexing of the body. Therefore, a single term for body flexing and presentation angle was used when investigating variance.

\section{RESULTS}

Sightings of basking sharks were made around the Hebrides off the west coast of Scotland, south of the Isle of Skye in a square ranging from approximately $57^{\circ} 10.4^{\prime} \mathrm{N}$ to $56^{\circ} 38.4^{\prime} \mathrm{N}$, and $06^{\circ} 53.8^{\prime} \mathrm{W}$ to $05^{\circ} 48.0^{\prime} \mathrm{W}$ (Figure 4 ). The majority of the sharks encountered were close to the island of Hyskeir in water depths of around $20 \mathrm{~m}$. Basking sharks were encountered on 9 days during these surveys. The numbers of sharks sighted each day ranged from 1 to 16 individuals with a total of 53 sightings. The 'groups' of sharks observed, ranged from large, loose aggregations of 5-10 or more sharks, to lone animals or several sharks associating more closely together. On most occasions, feeding behaviour was observed, but possible 'social' behaviour as described by Maxwell (1952) and Fairfax (1998) was also observed on several occasions, with two or more sharks closely following each other, nose to tail. In these situations it was not possible to clearly track individuals. Thus all the data presented here relates to what was assumed to be feeding behaviour. Breaching, a quite common behaviour which may also have a social purpose, was also observed.

A total of 24 tracks of individual sharks' movements were analysed from seven different days. Tracks were discarded if there was a possibility of confusion between individuals being tracked. Useable tracks of surface movements together with length measurements were obtained for 10 sharks (Table 1). These ranged in duration from between 20 and 150 minutes. Average swimming speeds $(V)$ based on total path length divided by total time are also given in Table 1 . There were some breaks in tracking caused by manoeuvring the vessel into a better location, or the shark showing insufficient dorsal fin to allow measurements from video. These are illustrated as breaks in Figure 5 and occurred for an average of around $30 \%$ of each track.

To investigate the possible effects of surface water movements on overall shark movement, tracks of the drifting buoy were examined and divided into segments of approximately straight line movement. There were six segments of track with combined shark and drift buoy data. For each of these segments the overall movement of the shark resolved along the vector of drift buoy movement divided by the magnitude of the drift vector, was calculated. The mean value of $0.2(\mathrm{SD}=1.2)$ was not significantly different from o (indicating no correlation between shark movement and surface drift), or 1 (indicating a strong correlation- $t$-test, $\mathrm{df}=5$, $P>0.05)$. Given this lack of a clear relationship and a mean drift rate of $0.14 \mathrm{~ms}^{-1}$ which was relatively small compared to shark swimming speeds, all analyses were conducted using movements over the ground rather than attempting to adjust for movement through the water.

Visual examination of plots of the tracks showed a general pattern of swimming behaviour alternating between periods with a high rate of turning keeping the shark within a limited area, followed by straight line movement (Figure 5). These two movement types were approximately classified by the ratio of the straight line distance travelled in a five minute interval to the total path length. Tracks where this ratio was less than 0.7 were classified as having a high turning rate whereas those greater than 0.7 were classified as straight line movement. One possibility is that a high turning rate was related to feeding and that straight line movement was related to searching for concentrations of plankton between high density patches. However, it was not

Table 1. Details of tracks for 10 individual sharks, including details of duration, speed and total distance.

\begin{tabular}{|c|c|c|c|c|c|c|}
\hline Shark & $\begin{array}{l}\text { Duration of } \\
\text { tracking (hours) }\end{array}$ & $\begin{array}{l}\text { Number of } \\
\text { measurements } \\
\text { of location }\end{array}$ & $\begin{array}{l}\text { Mean interval between } \\
\text { locations used for swim } \\
\text { speed measurements } \\
\text { (seconds) }\end{array}$ & $\begin{array}{l}\text { Mean swim speed } \\
\text { (total distance/ } \\
\text { total time) } \mathrm{ms}^{-1}\end{array}$ & $\begin{array}{l}\text { Mean of individual } \\
\text { measurements } \mathrm{ms}^{-1}\end{array}$ & $\begin{array}{l}\text { SD of individual } \\
\text { speed measurements }\end{array}$ \\
\hline A & $2: 52$ & 147 & 51 & 0.49 & 0.55 & 0.26 \\
\hline B & $2: 50$ & 140 & 51 & 0.59 & 0.61 & 0.26 \\
\hline $\mathrm{C}$ & $0: 52$ & 31 & 63 & 0.58 & 0.62 & 0.33 \\
\hline $\mathrm{D}$ & $1: 00$ & 64 & 51 & 0.63 & 0.70 & 0.27 \\
\hline $\mathrm{E}$ & $0: 33$ & 34 & 45 & 0.71 & 0.74 & 0.26 \\
\hline $\mathrm{F}$ & $1: 45$ & 78 & 51 & 0.61 & 0.62 & 0.27 \\
\hline G & $0: 59$ & 20 & 49 & 0.73 & 0.74 & 0.28 \\
\hline $\mathrm{H}$ & 1:08 & 48 & 54 & 0.65 & 0.70 & 0.30 \\
\hline I & $0: 30$ & 30 & 59 & 0.67 & 0.67 & 0.28 \\
\hline $\mathrm{J}$ & $1: 36$ & 73 & 60 & 0.63 & 0.67 & 0.26 \\
\hline
\end{tabular}




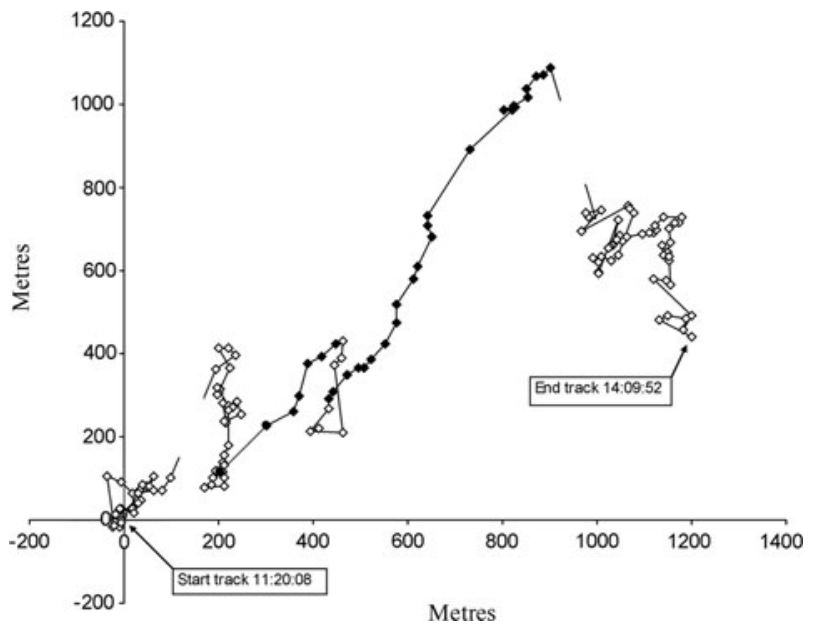

Fig. 5. The track of the movements of Shark B, which was tracked for 2 hours and 50 minutes. It shows movement patterns alternating between periods with a high rate of turning (open diamonds) keeping the shark within a limited area, followed by straight line movement (filled diamonds). Breaks in the track are due to manoeuvring of the study vessel or the dorsal fin not being clearly visible on the video image.

consistently possible to observe whether the mouth was open from the distances at which sharks were being tracked. In order to test whether there was a difference in swimming speed between high turn rate and straight line tracks average swim speeds for each divided by the overall average swim speed for that individual shark were compared. For the eight tracks with both straight line movement and a high turning rate, there was no significant difference between these normalized swim speeds (paired $t$-test, $\mathrm{df}=7$, $P=0.6$ ). Thus all data for each individual were used for comparison of body length to swim speed.

Table 2 gives the length measurements of the 10 individual sharks that were successfully tracked and measured. The mean ratio of $\mathrm{S} / \mathrm{T}$ was $0.87(\mathrm{SD}=0.12)$. This compares well and is not significantly different ( $t$-test, $\mathrm{df}=16, P>0.05$ ) with the mean figure of $0.85(\mathrm{SD}=0.03)$ based on the measurements of Matthews \& Parker (1950). This suggested no systematic differences in body proportions between the sharks observed in this study and the measured carcasses.

Within batches of images the mean SD was $0.09 \mathrm{~m}$. This suggests a value of $\sigma$ in equation 5 of 0.09 . If body flex is taken from a uniform distribution of $1-1.09$ and range errors are taken from a normal distribution with mean o and $\mathrm{SD} 0.034$ then equation 5 would suggest a combined $\mathrm{SD} / X$ of 0.1 . For measurements of $S$ the mean $\mathrm{SD}$ was $0.11 \times \hat{S}$ and for $T$ it was $0.09 \times \hat{T}$. Thus, the observed variance could be explained by equation 5 . Nevertheless, when extrapolated to the total length $L$, the SD values in Table 2 are quite high and indicate the value in obtaining as many measurements as possible.

Linear regression indicated a significant relationship between $\log L$ and $\log V$ given by $\log V=0.33 \log L-0.44$ $\left(r^{2}=0.69, \mathrm{df}=8, P<0.01\right)$. The $95 \% \mathrm{CI}$ for the slope was $0.18-0.48$. Regression for all sharks using dorsal to tail measurements rather than all the data explained slightly more of the variance $\left(\log V=0.34 \log T-0.37 ; r^{2}=0.74, \mathrm{df}=8, P\right.$ $<0.05$ ). The smallest shark (Shark A) was an outlier in terms of length, but the regression remained significant $(\log V=$ $\left.0.59 \log T-0.50 ; r^{2}=0.49, \mathrm{df}=7, P<0.05\right)$ when this individual was excluded. Figure 6 shows these results together with data from feeding sharks given by Sims (2000) and the optimal cruising model $V=0.503 L^{0.43}$ of Weihs \& Webb (1983). The swimming speeds observed in this study were slower in relation to body length than the observations of Sims (2000) and the Weihs \& Webb (1983) model.

\section{DISCUSSION}

Measurements of both location and length are subject to errors. Locations require both accurate range and bearing data. The combination of random errors in both these parameters will tend to lead to swim speed being overestimated. However, visual inspection of plots of the shark tracks which frequently showed straight line movements suggested that errors in location should not cause substantial bias in swim speed estimates. Nevertheless, the variance in the point estimates of swim speed (Table 1) show the need for tracks of a sufficient duration. Similarly, the variance in length measurements indicates the need for multiple measurements from the same individual. Ideally these would also be independently validated by an alternative method of measurement, but this was not possible in this study. The study vessel was not sufficiently manoeuvrable to attempt close approaches to sharks for direct visual estimation of length as described by Sims (2000). Although the methods used in this study are not very precise, this is offset by the ability to collect large sample sizes

Table 2. Length measurements. Best estimate is based on mean of all measurements. $\mathrm{N}$ refers to the number of measurement clusters from sequences of images taken at least one minute apart.

\begin{tabular}{|c|c|c|c|c|c|c|c|c|c|c|c|c|}
\hline \multirow[t]{2}{*}{ Shark } & \multicolumn{3}{|c|}{ Dorsal to tail $(\mathrm{T})$} & \multicolumn{3}{|c|}{ Snout to dorsal (S) } & \multicolumn{3}{|c|}{$\begin{array}{l}\text { Direct measurement of } \\
\text { snout to tail }(S+T)\end{array}$} & \multicolumn{3}{|c|}{$\begin{array}{l}\text { Best estimate of } \mathrm{L} \text { based on } \\
\text { all data }\end{array}$} \\
\hline & $\mathbf{N}$ & Mean (m) & SD & $\mathbf{N}$ & Mean (m) & SD & $\mathbf{N}$ & Mean (m) & SD & $\mathbf{N}$ & Mean (m) & SD \\
\hline A & 9 & 1.42 & 0.23 & 8 & 1.24 & 0.22 & & & & 17 & 2.35 & 0.38 \\
\hline $\mathrm{B}$ & 7 & 3.13 & 0.41 & 2 & 3.12 & 1.10 & & & & 9 & 5.36 & 0.97 \\
\hline $\mathrm{C}$ & 4 & 3.03 & 0.31 & 2 & 3.35 & 0.04 & 1 & 7.04 & & 7 & 5.57 & 0.74 \\
\hline $\mathrm{D}$ & 10 & 3.55 & 0.27 & 2 & 2.51 & 0.34 & 1 & 5.95 & & 13 & 5.68 & 0.64 \\
\hline $\mathrm{E}$ & 4 & 3.67 & 0.29 & 1 & 3.12 & & & & & 5 & 6.07 & 0.44 \\
\hline $\mathrm{F}$ & 13 & 3.48 & 0.37 & 2 & 2.71 & 0.15 & & & & 16 & 5.76 & 0.64 \\
\hline G & 3 & 3.97 & 0.15 & 3 & 3.35 & 0.04 & 1 & 7.19 & & 7 & 6.43 & 0.24 \\
\hline $\mathrm{H}$ & 7 & 3.45 & 0.37 & 5 & 2.61 & 0.36 & 4 & 6.37 & 0.59 & 16 & 5.45 & 0.70 \\
\hline I & 2 & 3.05 & 0.23 & 6 & 2.98 & 0.26 & & & & 9 & 5.36 & 0.52 \\
\hline $\mathrm{J}$ & 13 & 3.12 & 0.30 & 3 & 2.46 & 0.28 & & & & 16 & 5.10 & 0.54 \\
\hline
\end{tabular}




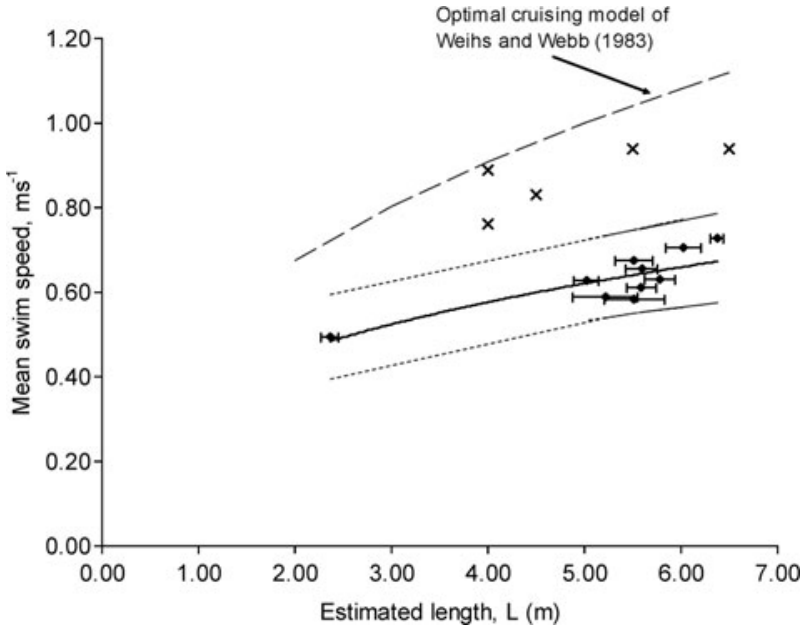

Fig. 6. Filled diamonds indicate swimming speed (total track length/tota time) against mean body length for 10 individual basking sharks. Error bars indicate standard error of mean body length. The solid line indicates the regression analysis with dotted lines showing the 95\% confidence limits for individual data points. Crosses indicate data points from table 1 of Sims (2000).

without the need for close approaches to sharks. The variance of the observed length measurements was within the range predicted by simple simulations and systematic bias related to the flexing of the shark's body should be less than $10 \%$.

The significant correlation between swim speed and body length is potentially important for theoretical studies of energy requirements in relation to body size. The mean swimming speeds observed for sharks in this study were slower than both the predicted feeding and cruising speeds suggested by Weihs \& Webb (1983). The observed swim speeds of between 0.49 and $0.73 \mathrm{~ms}^{-1}$ were also lower than the range of values of $0.76-0.94 \mathrm{~ms}^{-1}$ reported by Sims (2000) for filterfeeding sharks. These observed speeds further support the conclusions of Sims (2000) that basking sharks swim at a rate slower than the optimal predicted value based on their size. The lengths measured in this study are also likely to be subject to a small negative bias due to flexing of the sharks body suggesting swim speeds from this study may be even slower in relation to body size. The differences between the results of this study and Sims (2000) suggest that basking sharks feeding in different areas swim at different speeds in relation to their length. Although the methods to determine swim speed are not directly comparable because this study measured mean speeds over the ground whereas Sims (2000) reported instantaneous speeds through the water, it seems unlikely that the differences in methodology could account for the magnitude of the observed differences.

There are several ways in which the findings in this study could be explored further. Measurements of swim speed and length across a wider range of body sizes would help to refine the relationship between $V$ and $L$. The single observation of a small shark in our data set undoubtedly has a large influence on the estimates. A significant relationship with speed increasing with body size remained when this individual was excluded although the regression slope was different. In addition, the overall estimates of $L$ from this study relied on measurements from carcasses over a limited range of body sizes which did not include the smallest shark observed. There appeared to be a slightly stronger relationship between $V$ and $T$ compared to $V$ and $L$ which may be indicative of differential growth between individuals affecting swimming speeds.

\section{ACKNOWLEDGEMENTS}

This work was funded and conducted by the International Fund for Animal Welfare. We would like to thank those who helped on 'Song of the Whale' during the field work; Kara Brydson, Irene Bystedt, Alison Gill, Helen McLachlan and Nick Tregenza. In addition we are also very grateful to Christopher Swann, Colin Speedie, David Sims and Steve Coombe for advice and information they provided whilst planning and conducting the project.

\section{REFERENCES}

Denardo C., Dougherty M., Hastie G., Leaper R., Wilson B. and Thompson P.M. (2001) A new technique to measure spatial relationships within groups of free-ranging coastal cetaceans. Journal of Applied Ecology 38, 888-895.

Fairfax D. (1998) The basking shark in Scotland. Natural history, fishery and conservation. East Linton, Scotland: Tuckwell Press.

Gordon J.C.D. (1990) A simple photographic technique for measuring the length of whales from boats at sea. Report of the International Whaling Commission 40, 581-588.

Gordon J.C.D. (2001) Measuring the range to animals at sea from boats using photographic and video images. Journal of Applied Ecology 38 , $879-887$.

Leaper R. and Gordon J. (2001) Application of photogrammetric methods for locating and tracking cetacean movements at sea. Journal of Cetacean Research and Management 2, 131-141.

Matthews L.H. and Parker H.W. (1950) Notes on the anatomy and biology of the basking shark (Cetorhinus maximus (Gunner)). Proceedings of the Zoological Society of London 120, 535-576.

Maxwell G. (1952) Harpoon at a venture. London: Rupert Hart-Davis.

Sims D.W., Fox A.M. and Merrett D.A. (1997) Basking shark occurrence off south-west England in relation to zooplankton abundance. Journal of Fish Biology 51, 436-440.

Sims D.W. and Quayle V.A. (1998) Selective foraging behaviour of basking sharks on zooplankton in a small-scale front. Nature 393, $460-467$.

Sims D.W. (1999) Threshold foraging behaviour of basking sharks on zooplankton: life on an energetic knife edge? Proceedings of the Royal Society, London, B 266, 1437-1443.

Sims D.W. (2000) Filter-feeding and cruising swimming speeds of basking sharks compared with optimal models: they filter-feed slower than predicted for their size. Journal of Experimental Marine Biology and Ecology 249, 65-76.

Videler J.J. (1993) Fish swimming. London: Chapman and Hall, pp. 288. and

Weihs D. and Webb P.W. (1983) Optimization of locomotion. In Webb P.W. and Weihs D. (eds) Fish biomechanics. New York: Praeger, pp. $339-371$.

\section{Correspondence should be addressed to:}

C. Lacey International Fund for Animal Welfare 87-90 Albert Embankment, London, SE1 7UD email: clacey@ifaw.org 